\title{
Mãe, cadê o bebê? Repercussões do nascimento prematuro de um irmão
}

\author{
Mom, where is the baby? Repercussions of \\ the premature birth of a sibling
}

\author{
Paula Nunes MOUSQUER ${ }^{1}$ \\ Lívia Caetano da Silva LEÃO' \\ Diogo Felipe KEPLER ${ }^{2}$ \\ Cesar Augusto PICCININI ${ }^{1}$ \\ Rita de Cássia Sobreira LOPES
}

\section{Resumo}

O objetivo deste artigo foi investigar as repercussões do nascimento prematuro do bebê sobre o(s) seu(s) irmão(s), sob a perspectiva materna, durante a internação do recém-nascido na Unidade de Terapia Intensiva Neonatal. O estudo contou com a participação de 37 mães, entrevistadas no $15^{\circ}$ dia após o parto. Elas responderam a instrumentos que contemplaram dados demográficos familiares, informações clínicas do bebê e da mãe, e a experiência da maternidade no contexto da prematuridade. A entrevista sobre maternidade continha questões acerca do irmão do bebê, cujas respostas foram examinadas a partir de análise de conteúdo qualitativa. Os resultados revelaram alteração na rotina dos irmãos em razão da maior ausência materna. Os sentimentos e reações dos irmãos incluíram questionamentos, preocupações, ciúme e ansiedade, ao lado de contentamento e curiosidade. A visita do irmão ao bebê prematuro não foi permitida por alguns hospitais. Evidencia-se a importância de os irmãos serem atendidos em suas necessidades de cuidado nesse período de hospitalização do bebê.

Palavras-chave: Irmãos; Nascimento prematuro; Unidades de Terapia Intensiva Neonatal.

\begin{abstract}
The aim of the present paper was to investigate the repercussions for a sibling of a premature birth, from the mother's perspective, during the baby's hospitalization in a Neonatal Intensive Care Unit. Thirty-seven mothers were interviewed on the $15^{\text {th }}$ day after delivery. They answered questionnaires on family demographic data, clinical information on the baby and the mother, as well as an interview about the experience of motherhood in the context of prematurity. This interview included questions regarding the baby's sibling. The answers were examined based on qualitative content analysis. The results revealed alterations in the sibling's routine as a consequence of the mother's absence. The siblings' reactions and feelings included doubts, worries, jealousy, anxiety, but also satisfaction and curiosity. Visits to the

$\checkmark v \nabla$

1 Universidade Federal do Rio Grande do Sul, Instituto de Psicologia, Programa de Pós-Graduação em Psicologia. R. Ramiro Barcelos, 2600, sala 108/111, Santa Cecília, 90035-003, Porto Alegre, RS, Brasil. Correspondência para/Correspondence to: R.C.S. LOPES. E-mail: <sobreiralopes@portoweb.com.br>.

2 Universidade Federal de Ciências da Saúde de Porto Alegre, Curso de Psicologia. Porto Alegre, RS, Brasil.

Apoio: Coordenação de Aperfeiçoamento de Pessoal de Nível Superior e Conselho Nacional de Desenvolvimento Científico e Tecnológico (Processo no 575250/2008-9).
\end{abstract}


premature baby were not allowed in some hospitals. There was evidence of the importance of caring for and attending to the needs of siblings during this period of the baby's hospitalization.

Keywords: Siblings; Premature birth; Neonatal Intensive Care Unit.

Atualmente o nascimento prematuro de um bebê pode ser considerado um fenômeno relativamente comum, já que cerca de $10 \%$ dos nascimentos registrados no Brasil ocorrem dessa forma (Brasil, 2009). De acordo com a World Health Organization (WHO, 2009), o nascimento prematuro é aquele ocorrido com menos de 37 semanas de gestação. $O$ bebê nascido nessa condição encontra-se biologicamente imaturo para a vida extrauterina (Behrman \& Butler, 2007), necessitando portanto de um ambiente onde possa se desenvolver e amadurecer - a chamada Unidade de Tratamento Intensivo Neonatal (UTI Neo).

Autores têm caracterizado o nascimento prematuro como um evento estressante para todos os integrantes da família do recém-nascido. Tanto os pais do bebê quanto os irmãos passam a vivenciar as consequências advindas da nova situação familiar (Cahmi, 2005; Valansi \& Morsch, 2004). O nascimento prematuro pode ser considerado um evento potencialmente traumático para o irmão do bebê (Cahmi, 2005), uma vez que rompe a previsibilidade de seu mundo familiar (Oehler \& Vileisis, 1990).

Nesse sentido, os pais referem a dificuldade do irmão, principalmente se for criança, em compreender esse evento, já que se cria uma expectativa com relação à chegada do bebê e, de repente, a mãe volta para casa sem barriga e sem bebê. A partir de então, o irmão pode passar a apresentar muitas dúvidas sobre as causas da hospitalização do recém-nascido (Morsch \& Braga, 2003). Questões como: "Por que ele nasceu antes do tempo?", "Quanto tempo ele vai ficar no hospital?", "Quando ele vai vir para casa?", "Ele vai morrer?" e "Ele vai poder brincar?" são comumente dirigidas aos pais (Kleiber, Montgomery, \& Craft-Rosenberg, 1995).

Nesse novo cenário, o irmão pode apresentar diferentes reações. Autores relatam que os pais identificam, nos irmãos pré-escolares e escolares, o surgimento de distúrbios de alimentação e sono, bem como dificuldades relacionadas à escola, às rotinas diárias e ao relacionamento com colegas e professores (Morsch, Carvalho \& Lopes, 1997; Morsch $\&$ Braga, 2003). Além disso, verifica-se que é comum o irmão apresentar medo de perder o amor parental, insegurança em relação às mudanças na vida familiar, ambivalência em relação aos pais, bem como sentimentos de frustração e tristeza por ter de deixar o bebê no hospital (Morsch \& Braga, 2003).

Sugere-se que um dos aspectos que mais influenciam o estado emocional do irmão, nesse contexto, seja a separação entre ele e a mãe. Klaus e Kennell (1993) referem que, quando a separação ocorre de forma inesperada, como é o caso do parto prematuro, a angústia sentida pelo irmão é ainda maior. Possivelmente, o cuidado dos familiares tende a se direcionar aos irmãos do bebê, atenuando os efeitos adversos daquela separação. Nesse sentido, sabe-se que o pai pode proporcionar uma continuidade de cuidados e prover o reabastecimento emocional à criança (Cahmi, 2005). Além do pai, os avós e tios igualmente são referidos como familiares que podem auxiliar os irmãos nesse período de instabilidade familiar (Morsch \& Braga, 2003).

Outro aspecto importante é que, nos momentos em que a mãe sai da UTI Neo e volta para casa, verifica-se que a forma como ela lida com o outro filho tende a ser permeada pelos próprios sentimentos de estresse e ansiedade inerentes à hospitalização do recém-nascido (Jones, 2007). Valansi e Morsch (2004) descrevem que, mesmo quando a mãe está presente junto ao filho mais velho, seus sentimentos e preocupações se concentram no bebê hospitalizado, o que é transmitido, de alguma forma, àquele filho. Assim, conforme Cahmi (2005), é comum que os irmãos passem a contar com pais emocionalmente carentes, preocupados e ansiosos. Portanto, mesmo nos momentos em que está fisicamente presente, a mãe pode, muitas vezes, não estar emocionalmente disponível 
às necessidades do filho mais velho, as quais passam a ser esquecidas nesse período de crise familiar (Beavis, 2007; Morsch \& Delamonica, 2005; Munch \& Levick, 2001). Como consequência, ele pode sentir-se rejeitado e abandonado (Cahmi, 2005; Garel, Bahuaud, \& Blondel, 2004).

Autores nacionais e internacionais têm enfatizado a importância de as instituições hospitalares acolherem os irmãos dos bebês nascidos prematuros (Bliss, 2011; Brasil, 2011; Levick et al., 2010; Munch \& Levick, 2001; Oehler \& Vileisis, 1990; Valansi \& Morsch, 2004). Atualmente, a política pública nacional, intitulada Método-Canguru, reforça a importância de a UTI Neo proporcionar programas de visitação direcionados aos irmãos dos bebês nascidos prematuros (Brasil, 2011).

De forma geral, há um consenso na literatura em relação aos benefícios do acolhimento aos irmãos de bebês prematuros. Dentre esses benefícios, destacam-se: 1) o maior entendimento sobre a necessidade de hospitalização do bebê e da permanência materna no hospital; 2) a redução de fantasias relacionadas ao nascimento e à hospitalização prolongada do bebê; 3) a diminuição dos medos, ansiedades e distúrbios psicossomáticos surgidos a partir do nascimento do bebê; 4) a adaptação emocional do irmão mais velho à situação; 5) a inclusão do bebê no processo familiar; e 6) a inauguração da ligação fraterna (Bliss, 2011; Brasil, 2011; Morsch \& Delamonica, 2005; Munch \& Levick, 2001; Oehler \& Vileisis, 1990; Valansi \& Morsch, 2004).

Por fim, é importante ressaltar que os estudos que envolvem os irmãos de bebês nascidos prematuros são realizados em proporção muito menor se comparados àqueles que focalizam as mães e pais (Johnston, 2010). Assim, a temática da experiência do irmão do bebê nascido prematuro é um campo ainda pouco explorado pela pesquisa científica (Cahmi, 2005; Gaal et al., 2010). Ainda, percebe-se que a maioria dos estudos encontrados nessa temática carece de análises minuciosas e de reflexões teóricas que possam embasar uma compreensão mais acurada sobre as vivências do irmão do bebê nascido prematuro. Evidencia-se, portanto, a importância da realização de estudos voltados aos irmãos, a fim de aprimorar o conhecimento científico nessa área.
Diante do exposto, o objetivo do presente estudo foi investigar as repercussões do nascimento prematuro de um bebê sobre seu irmão, sob a perspectiva materna, durante a internação hospitalar do bebê na UTI Neo. Em particular, buscou-se conhecer essas repercussões em termos de: a) rotina do irmão após o nascimento do bebê; b) reações e sentimentos apresentados pelo irmão diante do nascimento do bebê; e c) contato do irmão com o bebê.

\section{Método}

\section{Participantes}

Participaram do estudo 37 mães de bebês nascidos prematuros e que tinham outro(s) filho(s). As mães tinham idade entre 20 e 43 anos (Média = 30; Desvio-Padrão $=7$ ), nível de escolaridade variando do ensino fundamental incompleto ao ensino médio completo, e nível socioeconômico de baixo a médio-baixo. Todas residiam na região metropolitana de Porto Alegre. Dentre as principais causas da prematuridade dos recém-nascidos, destacaram-se a hipertensão arterial (30\%) e a pré-eclâmpsia (25\%). A idade gestacional dos bebês, ao nascimento, variou de 26 a 35 semanas (Média $=31$; Desvio-Padrão = 2,9), com peso entre 660 e 2280 g (Média = 1.405; Desvio-Padrão = 392).

Do total de mães, 67\% (25) possuíam apenas 1 filho além do bebê, $22 \%$ (8) possuíam 2 filhos, e $11 \%$ (4) possuíam 3 ou mais filhos. Quanto à faixa etária dos irmãos, 30\% (19) encontravam-se em idade escolar (entre 7 e 11 anos), 27\% (17) eram adolescentes (entre 12 e 18 anos), 23\% (15) eram pré-escolares (3 a 6 anos), 14\% (9) eram adultos (idade $>18$ anos) e $6 \%$ (4) eram bebês (entre 0 e 2 anos).

Todas as participantes integravam o projeto "Prematuridade e Parentalidade: do nascimento aos 36 meses de vida da criança" (PREPAR) (Lopes et al., 2012), que vem acompanhando 90 famílias de prematuros, nos três primeiros anos de vida. $\mathrm{O}$ objetivo do projeto é investigar a experiência da parentalidade e o desenvolvimento do bebê no 
contexto da prematuridade. Além disso, com uma subamostra, investigaram-se as contribuições de uma intervenção psicológica realizada durante a hospitalização do bebê. Trata-se de um estudo longitudinal envolvendo várias fases de coleta de dados: no $15^{\circ}$ dia após o parto, na pré-alta, no $3^{\circ}$ mês após a alta, e também no $12^{\circ}, 24^{\circ}$ e $36^{\circ}$ mês de vida da criança. Em cada uma das fases são realizadas entrevistas com a mãe e com o pai do bebê, além de avaliações do seu desenvolvimento, mediante a aplicação de diversos instrumentos. A pesquisa foi realizada em três hospitais que integram a rede pública de saúde Porto Alegre. O projeto foi aprovado pelo Comitê de Ética e Pesquisa da Universidade Federal do Rio Grande do Sul (Processo $\left.n^{\circ} 22009015\right)$ e pelos comitês de ética dos hospitais.

\section{Instrumentos}

As mães que aceitaram participar responderam à Entrevista de Dados Demográficos da Família (Núcleo de Infância e Família, Grupo de Interação Social, Desenvolvimento e Psicopatologia [NUDIF/GIDEP], 2009a) e à Ficha de Dados Clínicos do Bebê Pré-Termo e da Mãe/Pós-Parto (NUDIF/ GIDEP, 2009b), a qual enfoca aspectos gerais de saúde da mãe e do bebê durante o período pós-parto. Em seguida era feita a Entrevista sobre a Maternidade no Contexto da Prematuridade/Pós-Parto (NUDIF/GIDEP, 2009c), que consiste em uma entrevista estruturada, realizada de forma semidirigida, na qual a mãe era solicitada a falar sobre diversos temas relacionados à sua experiência de maternidade após o nascimento prematuro do bebê.

As mães dos bebês foram contatadas nas UTI Neo dos hospitais participantes, no $15^{\circ}$ dia após o parto, e convidadas a participarem da pesquisa. Após assinarem o Termo de Consentimento Livre e Esclarecido, aplicaram-se os instrumentos previamente mencionados. As entrevistas tiveram duração de 90 a 120 minutos, sendo realizadas em local reservado dentro dos próprios hospitais.

Foi realizada uma análise de conteúdo qualitativa (Laville \& Dione, 1999) para examinar as respostas das mães à entrevista. Para fins do presente 530 estudo, analisou-se o bloco de perguntas referentes ao irmão do bebê nascido prematuro, com questões como: "Como está sendo a rotina do teu outro filho desde a internação do bebê?", "Quem cuida dele quando estás aqui no hospital?", "Como ele está se sentindo?", "O que ele tem dito?", "Ele já visitou o bebê? Se sim, como foi a reação dele?". Após exaustiva leitura, as respostas foram analisadas com base em três eixos: a) rotina do irmão após o nascimento do bebê; b) reações e sentimentos do irmão diante do nascimento do bebê; e c) contato do irmão com o bebê.

\section{Resultados e Discussão}

\section{Rotina do irmão após o nascimento do bebê}

A principal alteração na rotina dos irmãos refere-se aos cuidados dispensados a eles. A maioria das Mães (M) (70\%) relatou ter ficado menos presente em casa, pois permaneciam longos períodos do dia junto ao bebê hospitalizado. Dessa forma, frente à maior ausência materna, os irmãos passaram a ser cuidados por outros familiares, como a avó materna e/ou paterna, o pai e/ou algum irmão mais velho:

"[irmão fica] com a minha mãe. Pratica-
mente o dia todo. Aí à noite fica comigo.
Antes passava o dia com ele. ... mudou
bastante, pra ele também" (M26, irmão de
7 anos); "Ele fica com minha sogra. Antes
era só eu e ele. Eagora é um monte de gente
diferente pra ele" (M14, irmão de 6 anos);
"Eu tenho que deixar ele [irmão de 9 anos]
por conta dele, porque eu preciso vir pra
cá. Eu fico descansada porque pelo menos
é o pai e o irmão que estão cuidando dele"
(M5, irmãos de 19 e 9 anos).

Cabe destacar a resposta espontânea das mães priorizando a rotina de cuidados, quando a pergunta referia-se à rotina de um modo geral, o que talvez denote a preocupação delas não só com o bebê hospitalizado, mas também com o(s) filho(s) que estava(m) em casa, vivenciando as repercussões impostas pela situação de prematuridade. Isso suge- 
re que as mães também se encontravam mobilizadas emocionalmente em relação às alterações na rotina de cuidados vivenciada por aquele(s) filho(s), como o fato de terem de que deixá-lo(s) sob os cuidados de familiares.

A grande maioria das mães deste estudo priorizou estar junto do bebê hospitalizado e, em consequência, mostrou-se menos disponível fisicamente ao(s) outro(s) filho(s), o que corrobora dados da literatura. No contexto do nascimento prematuro de um filho, o cuidado materno tende a se dirigir intensivamente ao filho frágil e imaturo biologicamente. Nesse cenário, o irmão do bebê pode passar a ser esquecido (Beavis, 2007; Morsch \& Delamonica, 2005; Munch \& Levick, 2001), ocupando um lugar mais discreto e periférico no contexto familiar.

No presente estudo, a maior alteração relatada pelas mães foi a sua menor presença junto ao(s) outro(s) filho(s). É plausível pensar que essa alteração tenda a gerar uma maior mobilização emocional no irmão cujo vínculo prévio com a mãe era marcado por afeto, acolhimento e cuidado. Nesse sentido, Gottlieb e Mendelson (1990), em estudo com irmãos de bebês nascidos a termo, apontam que a qualidade prévia da relação entre a mãe e o filho mais velho influencia na adaptação deste ao nascimento do bebê. Portanto, é possível pensar que, quanto melhor a qualidade dessa relação, maior tende a ser o impacto da ausência materna na vida do filho. Contudo, esse impacto pode ser minimizado por meio do auxílio oferecido por familiares. Tal auxílio proporciona uma continuidade de cuidados e possibilita o reabastecimento emocional à criança (Cahmi, 2005; Klaus \& Kennell, 1993; Morsch \& Braga, 2003). No presente estudo, constatou-se que a rede de cuidados era constituída pelos avós, pelos irmãos mais velhos e/ou pelo próprio pai.

Cabe destacar que três mães referiram uma alteração ainda mais intensa na rotina do irmão, que passou a morar em outra cidade após o nascimento do bebê. Essa alternativa surgiu diante da ausência de cuidadores, especialmente naquelas famílias em que a mãe precisou se mudar para Porto Alegre, a fim de ficar mais próxima do bebê: "Eu vim pra cá e ele ficou em outra cidade com a madrinha dele. Eu tive que deixar ele ali porque não tinha ninguém. Foi bem complicado no começo" (M34, irmão de 4 anos). Nos três casos, talvez os irmãos tenham se sentindo abandonados pelo seu meio familiar. Conforme apontam Valansi e Morsch (2004), o fato de ser mandado para longe de casa, após o nascimento prematuro do bebê, pode ser interpretado pelo irmão como uma punição pela existência de desejos infantis - referentes à não existência desse bebê -, comumente presentes durante a gestação. Assim, a vivência de ir para longe de casa pode intensificar o sentimento de culpa experimentado pelo irmão mais velho, reforçando a ideia de que ele foi o responsável por prejudicar o bebê e por impedir sua ida para casa (Cahmi, 2005; Jones, 2007; Valansi \& Morsch, 2004).

Através da verbalização de duas mães, verificou-se que a alteração na rotina do irmão também pode se dar em função de uma mudança na forma de cuidado materno oferecido:
"Eu vou pra casa daí a gente fica junto, faz os temas tudo junto, dorme junto. Aí de manhã ela acorda, fica comigo, aí de tarde ela vai pro colégio, daí eu venho pra cá. Mas ela tem me cobrado bastante, que eu venho todo dia, que ela quer eu mais em casa, por mais que ela não esteja em casa" (M21, irmã de 6 anos); "Eu chego em casa e tem toda aquela atenção com a minha filha. Ela quer jantar junto, ela quer olhar TV, ela quer ficar perto. Às vezes tu tá com o olho assim sabe, tu não quer dormir porque daí fica imagi- nando: 'pô, passa o dia inteiro com o meu irmão, chega aí, só quer dormir e não me dá atenção'" (M20, irmã de 16 anos).

Identifica-se, nesses dois casos, a tentativa das mães em compensar o tempo que permaneciam longe das filhas primogênitas. Tal tentativa possivelmente sustentava-se tanto pela culpa materna em deixar a filha maior para estar junto ao bebê, quanto pela demanda de cuidados advinda da criança/adolescente.

Por fim, poucas mães (16\%) referiram que a rotina do irmão não sofreu alterações. Tal percepção ocorreu em dois tipos de situações: a) nos 
casos em que a mãe se ausentava, para visitar o bebê na UTI Neo, apenas quando a criança ia para a escola/creche; e b) em alguns casos em que os irmãos eram adolescentes ou adultos e, assim, menos dependentes do cuidado materno.

Verifica-se que a ideia materna de não alteração da rotina refere-se à manutenção de um modo de funcionamento familiar anterior à chegada do bebê. Assim, essas mães, ou seguiram presentes junto aos filhos como anteriormente faziam, ou seguiram percebendo o filho como alguém que, mesmo antes do nascimento do bebê, já não precisava de tanto cuidado por parte delas. Nesses casos, supõe-se que, apesar de a rotina ter permanecido sem muitas alterações, a qualidade dos momentos vivenciados junto ao outro filho - seja ele criança, adolescente ou adulto -, fosse diferente daquela vivida no período anterior ao nascimento do bebê. Nesse sentido, apesar de estarem fisicamente presentes, as mães que vivenciam a hospitalização do bebê nascido prematuro podem estar menos disponíveis emocionalmente aos outros filhos (Beavis, 2007; Morsch \& Delamonica, 2005; Munch \& Levick, 2001). Essa menor disponibilidade emocional pode ser associada à emergência de alguns sentimentos maternos, como tristeza, ansiedade e preocupação com o bebê hospitalizado (Jones, 2007; Valansi \& Morsch, 2004).

\section{Reações e sentimentos apresentados pelo irmão diante do nascimento do bebê}

Muitas mães (41\%) destacaram que, frente ao nascimento prematuro, a reação mais comumente apresentada pelos irmãos foi o questionamento acerca do ocorrido e do estado clínico do bebê. Isso ocorreu principalmente entre os irmãos adolescentes e os pré-escolares, embora o conteúdo das perguntas tenha sido bastante distinto, dependendo da faixa etária.

Os irmãos em idade escolar e os adolescentes demonstraram compreender melhor o que é o nascimento prematuro, reconhecendo que o bebê não deixa de existir por não estar em casa ou na barriga da mãe. Nesse sentido, costumavam questionar so-

532 bre a saúde do bebê, seu estado clínico e a previsão de alta: "eles perguntam sempre: 'quantos quilos ela tá?' Porque só com 2 quilos que pode ir pra casa" (M3, irmãos de 18 e 14 anos e irmãs de 22, 8 e 7 anos). "Ela pergunta quanto ele tá mamando, se ele já aumentou de peso e o que ele fez" (M20, irmã de 16 anos).

Por outro lado, os irmãos mais novos (2 a 6 anos) perguntavam sobre o bebê por não entenderem o que aconteceu, onde estava o bebê, o porquê de ele estar no hospital, se ele realmente existia e o porquê de a mãe não trazê-lo para casa:

“[O irmão] diz: 'Ai, mãezinha'... daí corre para a minha barriga. Eu digo: 'não, filho, não é mais aqui que as maninhas estão, as maninhas estão lá no hospital'. Não entendeu ainda que eu já tive elas. Toda hora ele pergunta: 'mas tu não vai trazer as maninhas? Por que tu ganhou e deixou lá?'" (M8, irmão de 2 anos). "Ela diz pra mim: 'cadê a maninha? Cadê?' Tipo assim 'nasceu, todo mundo fala, mas por quê que eu não vejo?'" (M13, irmã de 2 anos). "Ele sempre via minha barriga e eu dizia que o bebê tava ali. Agora dizer que nasceu... 'Onde é que tá?' Ele pergunta: 'e ele toma mamá?' Eu digo: 'não, ele toma numa sondinha'" (M34, irmão de 4 anos). "Ele fica numa ansiedade perguntando pra mim: 'ele é muito pequeninho, ele tem que ficar grandinho pra vir pra casa né mãe?'" (M37, irmão de 5 anos).

Todas essas questões levantadas pelos irmãos de bebês nascidos pré-termo são obviamente esperadas (Kleiber et al., 1995; Morsch \& Braga, 2003). Morsch e Delamonica (2005), em pesquisa sobre os comportamentos dos irmãos durante a visitação ao bebê na UTI Neonatal, igualmente verificaram que o conteúdo das perguntas dos irmãos variou em função da faixa etária. As autoras constataram que os irmãos menores, em torno de até três anos de idade, ao entrarem na UTI Neonatal, tendiam a se dirigir apressadamente à incubadora e apresentavam grande necessidade de tocar no bebê, possivelmente para constatarem que ele era mesmo real. No presente estudo, as mães também referiram que os irmãos de 2 anos de idade apresen- 
tavam dúvidas acerca de quão real era o bebê que, de repente, passava a ocupar outro lugar que não a barriga da mãe. Quanto aos irmãos pré-escolares, Morsch e Delamonica (2005) constataram a maior tendência de perguntas sobre a situação do bebê e o motivo da internação. Tal tendência também pôde ser verificada no presente estudo, com questionamentos como "ele toma mamá?" e "ele é muito pequeninho, ele tem que ficar grandinho pra vir pra casa, né mãe?".

Frente à expressão de dúvidas e perguntas sobre o nascimento prematuro do bebê, é fundamental o acolhimento e a oferta de respostas, tanto por parte dos familiares quanto da equipe de saúde que cuida do bebê (Morsch \& Delamonica, 2005; Valansi \& Morsch, 2004). Isso pode ser feito por meio de conversas sobre o que está acontecendo com o bebê, sobre o tempo que a mãe precisará ficar no hospital junto a ele, e sobre o motivo da tristeza sentida pelos familiares (Valansi \& Morsch, 2004). Nesse sentido, é importante que o irmão crie uma narrativa sobre sua experiência, nomeando seus sentimentos e fantasias acerca do evento vivenciado (Jones, 2007).

A existência de tantas dúvidas e questionamentos pode estar relacionada também a diversos sentimentos e preocupações por parte dos irmãos. É plausível que estes apresentem preocupações quanto ao futuro do bebê e da família no contexto da prematuridade do recém-nascido (Gaal et al., 2010; Latva, Lehtonen, Salmelin, \& Tamminen, 2007; Taylor, 2008), como pode ser visto no seguinte relato: "às vezes eu to aqui no hospital e ele tá ligando pra saber como é que ela tá, ele se preocupa bastante" (M6, irmão de 13 anos). Apesar de somente três mães terem relatado a presença dessas preocupações, possivelmente outros irmãos igualmente estivessem preocupados e mobilizados com a situação clínica do bebê. Contudo, é possível que eles não tenham referido explicitamente suas preocupações, ou que as mães não tenham conseguido identificá-las por estarem muito voltadas ao bebê na UTI Neo.

Constatou-se também que algumas mães (18\%) mencionaram que os irmãos apresentaram ciúme após o nascimento do bebê, o que foi mani- festado em todas as faixas etárias, exceto entre os irmãos adultos: "o mais velho que estava mais revoltado. Ele diz: 'Ah, mãe, o que tu tem que ir? Tu não precisa ir, deixa o nenê lá. '" (M7, irmãos de 7 e 4 anos); "Ah eles estão muito ciumentos. A minha guria [menor] não entende sabe? Ela pensa que eu vou ficar com esse e não vou mais dar atenção pra eles..." (M10, irmão de 10 anos e irmãs de 15, 13, 8 e 7 anos) "Eu sinto que eles estão com um pouquinho mais de ciúme, mais carentes, querem mais atenção" (M30, irmãos de 11 e 8 anos). Quanto ao ciúme, Bliss (2011) aponta que este é um sentimento esperado por parte do irmão frente à chegada prematura de um bebê, principalmente devido aos longos períodos em que ele passa a ser privado da presença materna. Segundo o autor, muitas vezes, o ciúme é dirigido aos próprios pais, através de comportamentos agressivos ou mesmo de apego.

Junto às manifestações de ciúme, o sentimento da falta materna foi explicitamente referido por três mães, que relataram que seus filhos sentiam a sua falta:

"acho que [o irmão se sente] meio triste né. De vez em quando ele liga: 'mãe tu não vai vir embora?' Ele é muito apegado né" (M25, irmão 13 de anos); "Ele pergunta que horário eu vou chegar. Porque ele também sente falta" (M26, irmão de 7 anos). "Eu vejo que ela sente saudade. Eu chego em casa e ela: 'Ah mãe, eu tava com uma saudade'" (M36, irmã de 4 anos).

Constatou-se também, a partir desses casos, que o sentimento de falta da mãe não ocorria somente com as crianças pequenas, podendo estar igualmente presente em escolares e adolescentes.

Outra reação manifestada pelos irmãos e relatada por algumas mães (13\%) foi a empolgação e o contentamento: "eles estão empolgados com o irmão, curiosos pra saber como é o irmão. 'Mãe, quando é que o bebê vai embora pra casa? Eu estou louco para ver ele'" (M1, irmãos de 12, 10 e 6 anos e irmãs de 9 e 7 anos); "Eles estão tão contentes que eles querem que ele vá logo pra casa" (M12, irmão de 11 anos e irmã de 9 anos). 
Algumas mães (13\%) também relataram a ansiedade dos filhos:

"Eu acho que ela está esperando o bebê, ansiosa. E os guris também, estão esperando ele, ansiosos" (M2, irmãos de 21 e 14 anos e irmã de 9 anos); "Todos os guris lá em casa tão ansiosos pra chegar o momento da gente levar ele pra casa" (M5, irmãos de 19 e 9 anos). "Ele tá ansioso, esperando o maninho pra brincar" (M15, irmão de 5 anos). "Ela tá um pouco apreensiva, um pouco nervosa. Não sei se é ansiedade da nenê voltar pra casa. ... Que a nenê não tá em casa" (M31, irmã de 12 anos).

Os relatos acima vão ao encontro do que tem sido relatado na literatura, que aponta ansiedade do irmão frente ao nascimento prematuro do bebê (Cahmi, 2005; Morsch \& Braga, 2003; Morsch \& Delamonica, 2005), o que não poderia ser diferente frente à complexidade da situação.

Por sua vez, a curiosidade dos irmãos também foi relatada por algumas mães (10\%): "eles [irmãos] estão bastante curiosos pra ver ela, pra ela ir pra casa de uma vez. Eles têm curiosidade de saber como ela é" (M3, irmãs de 22, 8 e 7 anos e irmãos de 18 e 14 anos).

Por fim, outra reação, expressa em dois casos, foi o adoecimento físico do irmão, ocorrido apenas em pré-escolares:

"ele até ficou doente. Infecção na garganta. Ele diz que eu tô abandonando ele" (M14, irmão de 6 anos). "A minha de três anos tá reagindo um pouco. Cada vez que alguém vem no hospital ela chora, pensa que eu vou morrer e não vou voltar. Ela ficou doente, chegou a baixar no hospital" (M22, irmãs de 8 e 3 anos).

Nesses casos, o sentimento de abandono e o intenso medo de perder a figura materna podem estar associados ao processo de adoecer, que pode ser influenciado por aspectos psicológicos. Evidencia-se o quanto essas crianças realmente necessitavam de cuidados, de um ambiente confiável e seguro para vivenciar as dificuldades impostas ao contexto familiar após a chegada prematura do 534 bebê.

\section{Contato do irmão com o bebê}

Algumas mães (22\%) referiram que os irmãos visitaram o bebê na UTI Neo, o que foi vivenciado como algo positivo: "Ah ela ficou encantada. Ela disse: 'Mãe, é do tamanho da minha boneca'" (M21, irmã de 6 anos). "Eu pedi uma autorização da psicóloga dela. A enfermeira leu e autorizou o guarda a deixar ela entrar. Porque ela tava querendo ver. Aí depois que viu, ela já acalmou assim..." (M24, irmã de 7 anos); "Domingo a minha guriazinha conseguiu entrar. Só via o mano por foto ... ficou encantada" (M29, irmã de 4 anos). O fato de a visitação ter sido apontada como benéfico ao irmão - algo que encanta e tranquiliza -, corrobora os dados da literatura, que destaca que a visitação contribui para seu maior entendimento sobre a situação e para a diminuição de suas fantasias e medos, bem como para a inauguração da ligação fraterna (Morsch \& Delamonica, 2005; Munch \& Levick, 2001; Valansi \& Morsch, 2004).

Ressalta-se que, neste estudo, as mães cujos filhos visitaram o bebê na UTI Neo, avaliaram, de forma unânime, que a visitação foi algo positivo para eles. Contudo, cabe considerar que, por vezes, também há a possibilidade de a visitação ser emocionalmente prejudicial ao irmão do bebê. Nesse sentido, Caron e Fonseca (2011) traçam um paralelo entre o encontro do irmão com o feto - através do exame de ultrassonografia pré-natal -, e o encontro do irmão com o bebê nascido prematuro. As autoras consideram que a imagem do feto e do bebê prematuro, ainda mais se este for muito pequeno, pode produzir um efeito desconcertante sobre o irmão, uma vez que experiências primitivas - como a impotência, o desamparo, o desconhecido, a solidão e a dependência -, costumam ser acionadas nesta situação.

Dessa forma, propõe-se que a visitação do irmão ao bebê nascido prematuro exista como uma possibilidade, e não como uma imposição. Quando for o caso, a visitação tem que ser cuidadosamente preparada e orientada, numa avaliação feita caso a caso. É importante que se considere a singularidade de cada irmão, sua idade e condição emocional, a existência de suporte familiar, o desejo de conhecer 
o bebê e, com relação ao bebê prematuro, a gravidade do seu estado clínico, o que permitirá que se julgue mais adequadamente se a visitação irá trazer mais benefícios ou prejuízos. É também importante lembrar que numa UTI Neo encontram-se inúmeros outros bebês em diferentes condições clínicas e familiares, com diferentes níveis de estresse, o que acaba sendo visto pelos visitantes, incluindo os irmãos que venham visitar o bebê.

Em 58\% dos casos deste estudo, a visitação não foi possível, devido às normas institucionais dos hospitais onde os bebês se encontravam. Cada hospital possuía regras diferentes quanto ao ingresso dos irmãos na UTI Neo, e um deles só permitia a entrada de adolescentes: "já pediram pra entrar, mas é a partir de 12 anos. Não pode entrar, elas disseram" (M7, irmãos de 7 e 4 anos); "Não [visitou]. Criança não pode entrar" (M36, irmã de 4 anos). 0 outro hospital só consentia a entrada de crianças acima de 6 anos de idade: "[não foram visitar] porque tem visita do irmão, mas é de 6 anos pra cima" (M27, irmãos de 5 e 2 anos). Neste, ainda, as visitas somente ocorriam às sextas-feiras: "não, eles não puderam entrar. Eles conhecem ele por foto, mas não de ver assim. Eu queria trazer, mas eles só podem vir na sexta. Durante o final de semana eles não podem entrar" (M12, irmãos de 11 e 9 anos). Por fim, em um hospital só era permitida a visita dos pais do bebê: "não, não dá [para irmãos visitarem]. Aqui é só pai e mãe que entra" (M3, irmãos de 18 e 14 anos, irmãs de 22, 8 e 7 anos). "Ele quer ver a maninha, só que não deixam ele entrar" (M23, irmão de 9 anos).

Apesar das restrições, o acolhimento aos irmãos nas UTIs Neo é recomendado pelo Ministério da Saúde e consta no programa Método Canguru (Brasil, 2011). Isso objetiva a humanização do ambiente neonatal, sendo preconizado o acolhimento a todos os membros da família, com o intuito de preservar os vínculos afetivos familiares durante o período de hospitalização do recém-nascido (Brasil, 2011). Contudo, ainda há a necessidade de uma melhor implementação dessa proposta de cuidado junto às instituições hospitalares (Gooding et al., 2011), visando uma genuína mudança no modo de acolher o bebê nascido prematuro e sua família.
Outro impeditivo da visita, relatado no presente estudo, deveu-se à decisão de algumas mães (20\%) de não levar o irmão ao hospital: "Eu quero que eles esperem em casa, que é melhor pra mim" (M1, irmãos de 12, 10 e 6 anos e irmãs de 9 e 7 anos). "Não veio ainda. Eu não quero trazer ele, e ele ver o maninho daquele jeito, com aqueles negócios... porque ele vai fazer pergunta e eu não vou saber explicar" (M15, irmã de 21 anos e irmão de 5 anos). Pressupõe-se que, caso os três hospitais em questão neste estudo estivessem realmente disponíveis a promover o acolhimento aos irmãos dos bebês, as mães poderiam também encorajar-se ao desafio de levá-los ao hospital. Ao contar com uma equipe de saúde que acolhesse os irmãos, as mães provavelmente sentir-se-iam mais seguras e confiantes para igualmente acolher as dúvidas e os sentimentos despertados nos irmãos durante a visita.

Por fim, vale destacar que várias mães (25\%) relataram fazer uso da fotografia para intermediar o contato entre o irmão e o bebê prematuro: "Ele não pode ver o irmão né. Não pode entrar ali. Daí eu acho que ele não tem noção do que tá se passando, só o que a gente comenta com ele, que o irmão dele tá na UTI... Então, a gente mostra as fotos pra ele, pra ele ver [o bebê]." (M26, irmão de 7 anos). "Eles não conhecem ela ainda, só por foto. Agora que eu comecei a tirar foto. Antes eu não tirava, por causa dos aparelhos" (M27, irmãos de 5 e 2 anos). "Ela pediu pra ver, aí eu tirei foto, levei pra ela ver. Aí toda hora ela pede pra olhar as fotinhos dos manos" (M28, irmã de 5 anos). Os relatos acima revelam que a fotografia permitiu atender ao desejo de algumas mães de que os filhos mais velhos conhecessem os irmãos prematuros. Ademais, tal recurso permitiu que outras preservassem os filhos quanto a essas visitas, sem que abrissem mão de mostrar como o bebê se encontrava na UTI Neo. Portanto, a fotografia constitui-se em uma forma de apresentar os bebês aos seus irmãos e promover o primeiro encontro fraterno.

\section{Considerações Finais}

O nascimento prematuro de um bebê refere-se a uma condição marcada pela imprevisibilidade, 
interrompendo abruptamente um processo que necessita de nove meses para ser concluído. Nesse sentido, assim como o bebê não está preparado para nascer antes desse tempo, o irmão igualmente pode não estar preparado para esse contexto de prematuridade. Talvez os nove meses de gestação do bebê sejam não só o tempo necessário para o seu amadurecimento biológico, mas também para a preparação emocional no processo de tornar-se irmão.

No presente estudo evidenciou-se, no geral, que as repercussões do nascimento prematuro de um bebê para o irmão foram evidenciadas, na maioria dos casos, pelos seguintes aspectos: maior ausência materna, presença de outros cuidadores, existência de questionamentos acerca do nascimento/estado clínico do bebê, presença de sentimentos como ciúme, contentamento, ansiedade e curiosidade, pouco acesso à visitação ao bebê na UTI Neo, uso da fotografia como recurso à promoção do contato/encontro irmãos-bebês.

Um interessante aspecto verificado neste estudo foi a associação espontânea feita pelas mães, quando perguntadas sobre alterações na rotina do(s) filho(s) mais velho(s), referindo-se especificamente à rotina de cuidados vivenciada por ele(s). Esse achado pode ser um indício da preocupação das mães não só em relação ao bebê hospitalizado, como também em relação ao modo como seu(s) outro(s) filho(s) estava(m) sendo cuidado(s). Desse modo, nota-se a escuta apurada por parte das mães quanto às necessidades de cuidados de seu(s) outro(s) filho(s) no período de hospitalização do irmão prematuro, marcado pelo afastamento materno e permeado por dúvidas e incertezas.

Outro achado destacado é que a maioria dos irmãos não conseguiu ter acesso à visitação ao bebê na UTI Neo. Esse dado merece atenção, pois muitos dos irmãos impossibilitados de ver pessoalmente o bebê demonstravam desejo de visitá-lo. Tal achado levanta reflexões sobre o papel das instituições hospitalares na vivência dos irmãos, que muitas vezes não são atendidos em suas demandas. Assim, reforça-se a importância de que as instituições hospitalares possam estender ao(s) irmão(s) o cuidado despendido ao bebê.
Cabe ressaltar que os achados foram obtidos mediante a análise da perspectiva materna. Talvez as repercussões do nascimento prematuro de um bebê ao irmão fossem relatadas de outra forma, caso outro membro da família participasse da pesquisa. Em especial, sugere-se que investigações sejam realizadas diretamente com o irmão, para que se possa ter acesso mais direto à sua própria experiência.

Ademais, pesquisas podem ser realizadas de forma a aprofundar o conhecimento científico existente sobre o irmão do bebê nascido prematuro. Como exemplo, poder-se-ia investigar a influência da condição de saúde do bebê nas vivências do irmão. É interessante também avaliar a influência dos amigos do irmão e das instituições às quais ele está vinculado - como a escola, a faculdade, o trabalho e as demais instituições existentes na comunidade -, na forma como ele experiencia o nascimento e a hospitalização do bebê. O campo de possíveis investigações quanto ao fenômeno em questão é vasto, tendo em vista a reduzida produção científica com foco no irmão do bebê nascido prematuro. Conquanto achados importantes tenham sido evidenciados, há muitas lacunas no conhecimento sobre esta temática, as quais podem e merecem ser preenchidas com novos estudos.

\section{Referências}

Beavis, A. G. (2007). What about brothers and sisters? Helping siblings cope with a new baby brother or sister in the NICU. Infant, 3(6), 239-242.

Behrman, R. E., \& Butler, A. S. (2007). Preterm birth: Causes, consequences, and prevention. Washington, D.C: The National Academies Press.

Bliss (2011). Community health professionals' information guide: Supporting families of premature and sick babies following discharge from hospital ( $2^{\text {nd }}$ ed.). London: Bliss. Retrieved November 12, 2012, from http://www.bliss.org.uk/wp-content/uploads/2011/11/ CPIG.pdf

Brasil. Ministério da Saúde. (2009). Datasus: Tecnologia da Informação a Serviço do SUS. Recuperado em outubro 10, 2012, de http://tabnet.datasus.gov.br/cgi/ deftohtm.exe?sinasc/cnv/nvrs.def

Brasil. Ministério da Saúde. (2011). Atenção humanizada ao recém-nascido de baixo peso: método canguru. Brasília: Editora do Ministério da Saúde. 
Camhi, C. (2005). Siblings of premature babies: Thinking about their experience. Infant Observation, 8(3), 209-233.

Caron, N. A., \& Fonseca, M. M. (2011). A presença de irmãos no exame de ultrassonografia pré-natal. Revista de Psicanálise da SPPA, 18(2), 417-442.

Gaal, B. J., Pinelli, J., Crooks, D., Saigal, S., Streiner, D. L., \& Boyle, M. (2010). Outside looking in: The lived experience of adults with prematurely born siblings. Qualitative Health Research, 20(11), 1532-1545.

Garel, M., Bahuaud, M., \& Blondel, B. (2004). Conséquences pour la famille d'une naissance très prématurée deux móis après le retour à la maison. Résultats de l'enquête qualitative d'EPIPAGE. Archives de pédiatrie, 11, 1299-1307.

Gooding, J. S., Cooper, L. Z., Blaine, A. I., Franck, L. S., Howse, J. L., \& Berns, S. D. (2011). Family support and family-centered care in the neonatal intensive care unit: Origins, advances, impact. Seminars in Perinatology, 35(1), 20-28.

Gottlieb, L. N. \& Mendelson, M. (1990). Parental support and firstborn girls' adaptation to the birth of a sibling. Journal of Applied Developmental Psychology, 11(1), 29-48.

Johnston, S. (2010). Sibling adjustment following the birth of a premature infant (Unpublished doctoral master thesis). Pace University, New York.

Jones, S. (2007). The baby as subject: The hospitalised infant and the family therapist. Australian and New Zealand Journal of Family Therapy, 28(3), 146-154.

Klaus, M., \& Kennell, J. (1993). Pais-bebê: a formação do apego. Porto Alegre: Artes Médicas.

Kleiber, C., Montgomery, L. A., \& Craft-Rosenberg, M. (1995). Information needs of the siblings of critically ill children. Children's Health Care, 24(1), 47-60.

Latva, R., Lehtonen, L., Salmelin, R. K., \& Tamminen, T. (2007). Visits by the family to the neonatal intensive care unit. Acta Paediatrica, 96(2), 215-220.

Laville, C., \& Dione, J. (1999). A construção do saber: manual de metodologia da pesquisa em ciências humanas. Porto Alegre: Artmed.

Levick, J., Quinn, M., Holder, A., Nyberg, A., Beaumont, E., \& Munch, S. (2010). Support for siblings of NICU patients: An interdisciplinary approach. Social Work in Health Care, 49(10), 919-933.

Lopes, R. C. S., Piccinini, C. A., Fleck, A., Steibel, D., Esteves, C. M., Leão, L. C. S., \& Mousquer, P. N. (2012). Prematuridade e parentalidade: do nascimento aos 36 meses de vida da criança (Projeto de pesquisa não-publicado). Universidade Federal do Rio Grande do Sul, Porto Alegre.
Morsch, D. S., Carvalho, M., \& Lopes, J. M. (1997). Programa de visitação dos irmãos aos bebês internados em UTI neonatal. Pediatria Moderna, 3(7), 481-488.

Morsch, D. S., \& Braga, N. A. (2003). Os irmãos do bebê. In M. E. L. Moreira, N. A. Braga, \& D. S. Morsch (Eds.), Quando a vida começa diferente: o bebê e sua família na UTI Neonatal (pp.97-106). Rio de Janeiro: Fiocruz.

Morsch, D. S., \& Delamonica, J. (2005). Análise das repercussões do programa de acolhimento aos irmãos de bebês internados em UTI neonatal: "lembraram-se de mim!". Ciência e Saúde Coletiva, 10(3), 677-687.

Munch, S., \& Levick, J. (2001). I'm special too: Promoting sibling adjustment in the neonatal intensive care unit. Health and Social Work, 26(1), 58-64.

Núcleo de Infância e Família, Grupo de Interação Social, Desenvolvimento e Psicopatologia. (2009a). Entrevista de dados demográficos da família (Instrumento não-publicado). Universidade Federal do Rio Grande do Sul, Porto Alegre.

Núcleo de Infância e Família, Grupo de Interação Social, Desenvolvimento e Psicopatologia. (2009b). Ficha de dados clínicos do bebê pré-termo e da mãe/pósparto (Instrumento não-publicado). Universidade Federal do Rio Grande do Sul, Porto Alegre.

Núcleo de Infância e Família,Grupo de Interação Social, Desenvolvimento e Psicopatologia. (2009c). Entrevista sobre a Maternidade no Contexto da Prematuridade/ Pós-Parto (Instrumento não-publicado). Universidade Fe-deral do Rio Grande do Sul, Porto Alegre.

Oehler, J. M., \& Vileisis, R. A. (1990). Effect of early sibling visitation in an intensive care nursery. Journal of Developmental \& Behavioral Pediatrics, 11(1), 7-12.

Taylor, L. S. (2008). A rites of passage analysis of the families experience of premature birth. Journal of Neonatal Nursing, 14(2), 56-60.

Valansi, L., \& Morsch, D. S. (2004). O psicólogo como facilitador da interação familiar no ambiente de cuidados intensivos neonatais. Psicologia: Ciência e Profissão, 24(2), 112-119.

World Health Organization. (2009). World health statistics 2009. Progress on health-related millennium development goals. Retrieved September 10, 2012, from http://www.who.int/whosis/whostat/2009/en/

Recebido em: 1/2/2013

Versão final em: 23/7/2013

Aprovado em: 13/9/2013 
